\title{
Mapping fractures remotely for earthquake hazard assessment by the use of topographic and seismic hypocenter data
}

Research tools are being developed in order to study the structure of fracture zones remotely by the use of topographic and seismic hypocenter data. These techniques have been employed in analyses of a complex segment of the San Andreas fault that includes its intersection with the Sargent fault in California, USA. These analyses also include the area where dominant surface rupturing resulted from the Loma Prieta earthquake of October 17, 1989. Results of this study indicate that a zone of complex fracturing marks the Pacific-North American plate boundary in this area. Brittle structures appear to be developing in response to uplift, northeast-southwest transpression, and right-lateral shear. Research also suggests that primary surface faulting on the San Andreas fault in this area has developed 2 kilometers northeast of the zone that now is mapped as the surface trace of the fault. Topographic fracture analyses identify the dominant regional fracture zones northeast of the mapped fault zone. These fracture zones correlate with the near-surface fracture zones that have been determined from seismic hypocenters and the surface projection of the modeled fault plane that has been determined from geodetic data. Right-lateral strikeslip motion, which was not observed in surface ruptures produced by the Loma Prieta earthquake, may be developing in this area.

\section{Introduction}

Digital fracture analysis techniques have been investigated since 1983 for the purpose of identifying potential fracture zones on the basis of their subtle topographic imprints and the distribution of their seismic hypocenters (Eliason, 1984; Eliason and Eliason, 1985a, b). We have used topographic data obtained from aerial and satellite platforms to develop and demonstrate the topographic analysis technique, and as part of this study, we have analyzed the seismic hypocenters that have been determined for a segment of the San Andreas fault south of San Francisco, California, USA. In addition, this work has included analysis of the available data on the surface topography for the study area located northwest of the Loma Prieta earthquake, which took place on October 17, 1989, at a depth of 17.6 $\mathrm{km}$ on the San Andreas fault.

Our analysis area (fig. 1) is centered over the Summit RoadSkyland Ridge area northeast of Santa Cruz, California. This area developed the most dominant surface ruptures that were related to the Loma Prieta earthquake (U.S. Geological Survey Staff, 1989). The objective of this research project was to correlate the potentially dominant surface fracture zones, as determined from topography, and the potentially active subsurface fracture zones, as determined from the aftershock sequence from the Loma Prieta event. The potential fracture zones that were identified in this complex segment of the fault show a strong spatial correlation between the fracture zones at the surface and the active subsurface fracture zones. We have devel

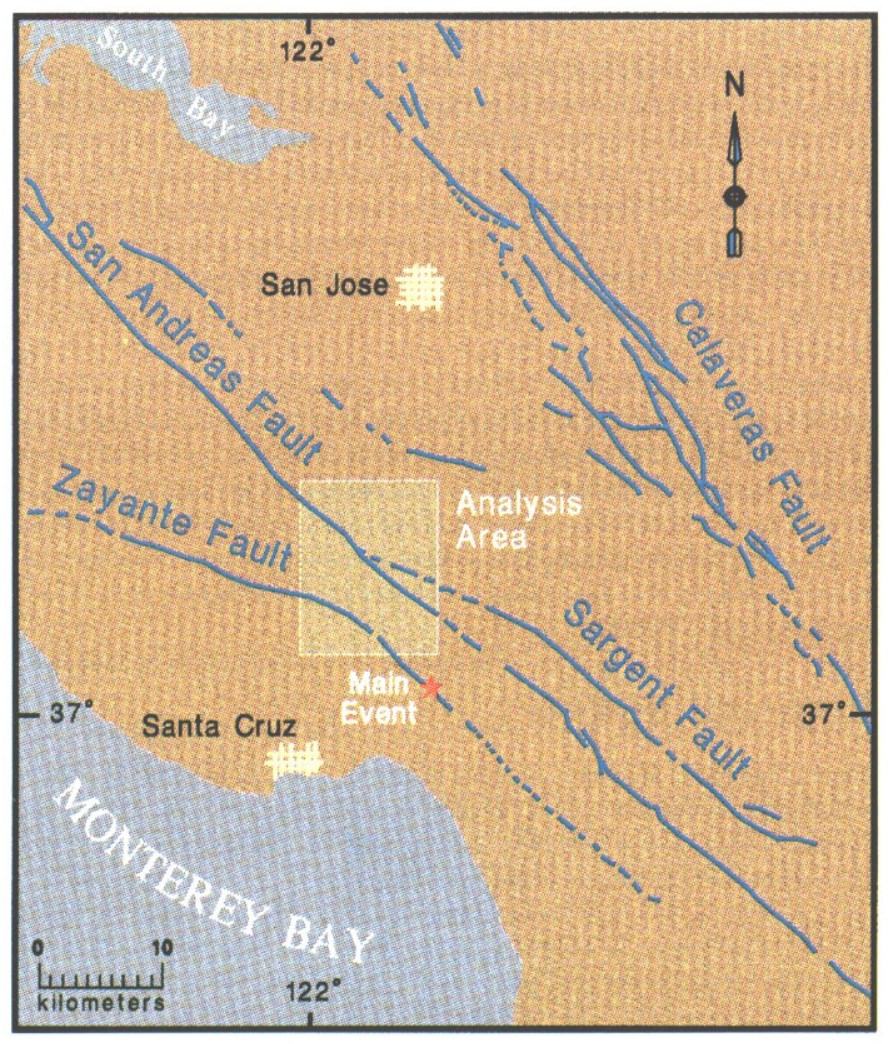

Figure 1.-Analysis area and dominant fault systems in the vicinity northeast of Santa Cruz, California, USA. Also shown is the location of the main event of the Loma Prieta earthquake of October 17, 1989. Dashed faults are inferred. 
oped a generalized structural model based on the potential fracture zones that we identified in the analysis area.

Digital fracture analysis techniques, which use topographic and seismic hypocenter data. provide geologists another structural analysis tool that will complement classic field mapping of geologic units and structural forms. Dominant near-surface fracture zones typically cut various geologic units and structural forms and can, in most areas, be mapped only locally by the field geologist. On the other hand. the spatial correlation of dominant fracture zones is not obvious in the field in most areas because of limited exposure. Therefore, the digital fracture analysis techniques that are being developed as part of this research program provide unique tools for mapping the regional correlations of these natural fracture systems. This mapping is done in three dimensions and uses the topographic imprint and seismic signature of the fracture systems.

\section{Analysis techniques}

Spatial fracture analysis techniques for the identification of dominant near-surface and subsurface fracture zones are based on the identification of locally planar segments of these zones. Near-surface planar scgments of fracture zones locally control the orientation of aligned topographic lows by influencing erosional processes. In the subsurface, these zones of crustal weakness accommodate local strain and produce clusters of seismic hypocenters. Topographic fracture analysis is limited primarily by the accuracy of the available topographic data that are required to define accurately the aligned topographic lows in three-dimensional space. These analyses also are limited currently to the identification of fracture zones having dips that range from $50^{\circ}$ to $90^{\circ}$. This limitation removes many of the structural identification problems that are associated with slope, bedding. and other shallowly dipping structural features. Research is focused on developing advanced algorithms that will be capable of handling the identification and classification of these shallowly dipping structures. Topographic data that are capable of defining $10-\mathrm{m}$ contours accurately at a scale of 1:24.000 or larger in areas having local relicf of $5000 \mathrm{~m}$ or greater have provided us the ability to define fracture zones in areas that are as small as $8 \mathrm{~km}$ by $8 \mathrm{~km}$. In contrast. the study of seismic hypocenters is not limited by the degree of dip and can be used to identify structures that dip from $0^{\circ}$ to $90^{\circ}$. Indeed, the analysis of the seismic hypocenters is limited primarily by the accuracy of the location of seismic events. The work presented here is based on seismic events recorded by the U.S. Geological Survey's seismic array on the San Andreas fault, which has relative location errors of significantly less than $300 \mathrm{~m}$ for the epicenter location and less than $600 \mathrm{~m}$ for the vertical location in the analysis area (Dietz and Ellsworth. 1990).

\section{Topographic analysis}

The topographic fracture analysis technique assumes that dominant underlying fracture systems locally control segments of valley and sidewall canyons and are expressed as aligned topographic lows. The three-dimensional location and orientation of such a topographic low can be thought of as a vector included in a fracture zone in threedimensional space. If a dominant fracture zone has developed in an area. the imprint of this zone will likely control several locally aligned topographic lows. All these topographic low vectors wil] lie in the plane of the dominant fracture zone (fig. 2). Coplanar analysis of these vectors defines the orientation and location of the fracture zone. Topographic low vectors that are not related to the dominant fracture zone will fail the coplanar analysis test and thus will be eliminated from the analysis. The coplanar test calculates poles to all possible planes that can be defined by three of the four vector end points. In order to pass the coplanar test. all these poles must be within specified limits of trend and plunge. An average plane strike. dip, and spatial location are calculated for each vector pair that passes the coplanar test. These coplanar detections are then sorted in order to identify dominant clusters of planes that fall within specified limits of orientation (strike and dip) and spatial location. Next, these potential fracture zones are ranked from the most dominant to the least dominant. The average fracture orientation and location in three-dimensional space for each cluster can be used in conducting classic structural analysis methods. as field measurements would be, or they can be used for projecting potential fracture zones to local altitude datums, as detailed later.

\section{Seismic hypocenter analysis}

Seismically active fracture zones develop along local zones of crustal weakness that are compatible with the local stress field. Seismic activity associated with these tectonic structures occurs dominantly within these fracture zones, but many events also occur on minor secondary structures during local deformation and dilation. In seismic fracture analysis, we assume that a significant number of these events will be located on the primary plane of a dominant fracture zone. This analysis technique uses the same coplanar algorithm that is involved in topographic fracture analysis. The algorithm uses four seismic hypocenters (in place of the four vector end points in the topographic analysis) for defïning coplanar sets of seismic events.

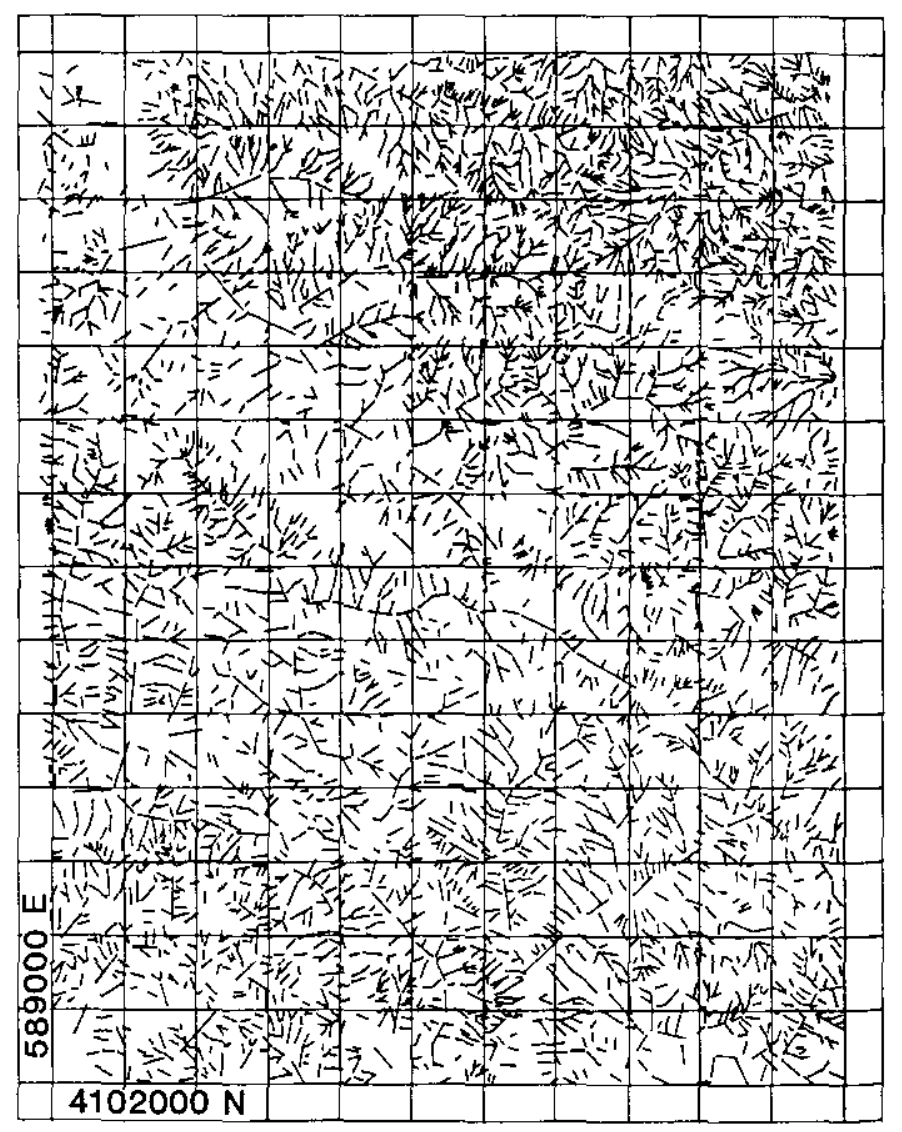

Figure 2. -Aligned valley vector segments of the topographic fracture studies of the analysis area are plotted on the Universal Transverse Mercator (UTM) projection, zone 10S, 1,000-m grid. 
All possible combinations of four events are analyzed in order to determine every possible seismically active set of planes. The coplanar test calculates poles to all the planes that can be defined by three of the four events. In order to pass the coplanar test, all these poles must fall within specified trend and plunge limits. As in the topographic fracture analysis, the coplanar seismic planes are sorted next for the purpose of identifying clusters of planes and for ranking the dominant fracture zones.

\section{Other seismic hypocenter analysis techniques}

Other research has been conducted on techniques for the identification of major crustal fractures that are seismically active in threedimensional space. This research includes the principal parameter method (Michelini and Bolt, 1986), the planes defined by three earthquakes (Fehler and others, 1987), and the counting box method (Rieken, 1985). In the principal parameter method (Michelini and Bolt, 1986), the strongest cluster of seismic events are fitted to a matrix of three perpendicular eigenvectors. Data from specific aftershock sequences are selected on the basis of time after a major event. A single average fault plane orientation and a location are determined for each sequence. In the method using planes defined by three earthquakes (Fehler and others, 1987), these planes are calculated for all possible combinations of three events in order to define every possible plane. Dominant fracture plane orientations then are selected from the planes identified. In the counting box method (Rieken, 1985), a series of thin counting boxes that have a specified strike and dip are superimposed over the seismic data in three-dimensional space. The strike and dip of the boxes are incremented by 5-degree steps through all the possible orientations, and the number of events in each box is recorded. Box orientations and locations containing high numbers of events define the potentially active fracture zones. The distribution of these events can be used then for defining a planar fracture, or a surface can be fitted to the events identified.

The four-point coplanar analysis algorithm, developed for the analysis of both topographic and seismic hypocenter data, has capabilities that avoid many of the limitations encountered by these other methods. If we use four vector end points, or four seismic hypocenters, for the initial identification of coplanar structures, this significantly reduces the number of potential structures that are identified initially. As a result, this eliminates most of the random planar structures and simplifies the cluster sorting. It also reduces the effect of the plane distribution that results from the shape of the input data set, which is a major limitation of three-point methods. Analyzing overlapping subregions within a study area allows us to resolve complex intersecting fault structures by the use of four-point coplanar analysis algorithms. In addition, analyses at various scales provide us information about both the dominant through-going fracture zones and the local fracture zones.

\section{Results and discussion}

Topographic fracture studies and seismic fracture studies have been conducted in the analysis area shown in figure 1. This area includes the lower half of the Los Gatos 7.5-minute quadrangle and the upper half of the Laurel 7.5-minute quadrangle. The area is $15 \mathrm{~km}$ from north to south and $12 \mathrm{~km}$ from east to west and includes the mapped intersection of the Sargent and San Andreas faults. It also includes most of the northwest half of the rupture zone that is associated with the Loma Prieta earthquake of October 17, 1989 (main event, fig. 1). Seismic aftershocks recorded from October through December 1989 within the analysis area number 997 events, located at depths ranging from $1 \mathrm{~km}$ to $20 \mathrm{~km}$, and were used for the seismic fracture analyses.

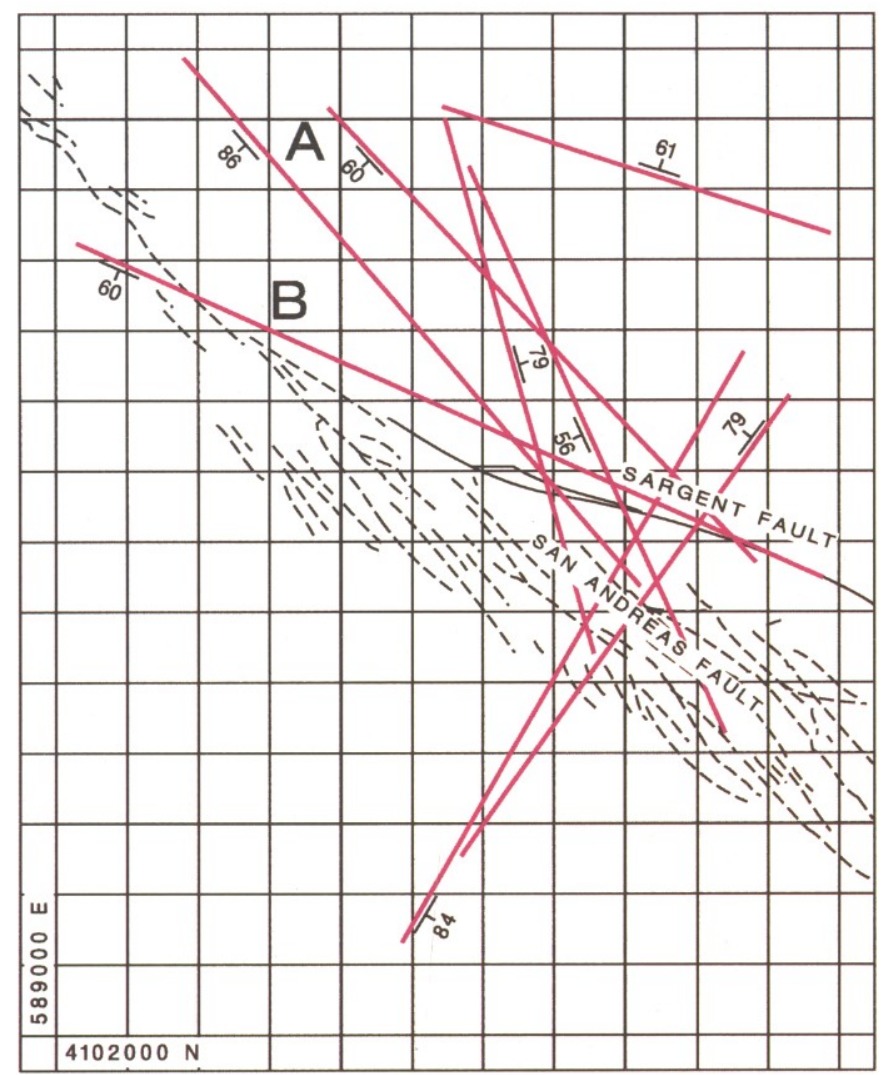

Figure 3.-Mapped surface faults that are related to the San Andreas (dashed black lines) and Sargent (solid black lines) fault zones (Brabb and Hanna, 1981) and potential fracture zones (red) and their dips. The potential fracture zones are related to both the San Andreas (A) and Sargent (B) fault zones and were identified by the regional topographic analysis projected to the 427-m- $(1,400-$ ft-) altitude datum, which is referenced to the UTM, zone 10S, 1,000-m grid.

The vectors for topographic lows (over 5,000) used in this research project were digitized from the topographic data that are available on the 1:24,000-scale 7.5-minute maps, which have a 12.2-m contour interval. These vectors, plotted in figure 2, are referenced at each end of an aligned topographic low by Universal Transverse Mercator (UTM) north and east coordinates and altitudes.

\section{Regional topographic analysis}

We conducted a regional study of the topographic low vectors in order to identify dominant through-going fracture zones. From this work, we selected potential fracture zones containing clusters of eight or more planes. These dominant through-going structures were defined by a total of 60 valley vectors from the more than 5,000 input vectors, and more than 98 percent of the input valley vectors were rejected in this regional analysis. The intercepts of these potential fracture zones with a near-surface datum $(427 \mathrm{~m})$ are plotted in figure 3. These regional potential fracture zones, which have typical lengths of $10 \mathrm{~km}$, are anticipated to be the most likely structures that may correlate with segments of major through-going fault systems.

The San Andreas and Sargent fault zones, as mapped by Brabb and Hanna (1981), are included in figure 3. The San Andreas fault zone correlates closely with the dominant surface rupture zone that 
developed in response to the Loma Prieta event and was mapped by the U.S. Geological Survey Staff (1989).

Regional potential fracture zones identified from the topography that are most likely related to the San Andreas fault ( $\mathrm{A}$ in fig. 3) are offset to the northeast of the mapped fault zone by approximately 2 $\mathrm{km}$. This 2-km offset corresponds with the surface projection of the fault plane as modeled by Lisowski and others (1990) from the geodetic data for this northwest segment of the rupture zone. The model developed from the geodetic data indicates that the rupture zone strikes $\mathrm{N} .44^{\circ} \mathrm{W}$, dips $70^{\circ} \mathrm{SW}$, and rakes $144^{\circ}$. This orientation agrees with the main shock mechanism (strike N. $50 \pm 15^{\circ} \mathrm{SW}$., rake $140^{\circ}$ ) determined from fault-plane solutions by Oppenheimer (1990). The geodetic modeling indicates that the coseismic deformation for this event can be explained by oblique slip $(1.66 \pm 0.05 \mathrm{~m}$ right-lateral strike slip and $1.19 \pm 0.06 \mathrm{~m}$ reverse slip) on a $37-\mathrm{km}-$ long buried rupture extending from $-5 \mathrm{~km}$ to $-17.5 \mathrm{~km}$ below the land surface. This event may not have produced measurable surface rupture, but the correlation between the modeled rupture zone projection to the surface and the dominant structures determined from the regional topographic analysis suggests that this is a zone of weakness that has influenced the surface topography. One of the dominant regional structures ( $\mathrm{B}$ in fig. 3) correlates closely with the mapped traces of the Sargent fault.

\section{Subregional seismic hypocenter analysis}

We conducted seismic hypocenter studies on overlapping subregions for the purpose of defining locally active, potential fracture zones. These studies used seismic hypocenters from three depth ranges: -1 to $-6 \mathrm{~km},-8$ to $-12 \mathrm{~km}$, and -14 to $-18 \mathrm{~km}$. From these analyses, we selected potential fracture zones that contained clusters of six or more planes. These seismically active zones have been projected to subsurface datums of $-3.5 \mathrm{~km},-10 \mathrm{~km}$, and $-16 \mathrm{~km}$, respectively, and are shown in figure 4.

The seismically active, potential fracture zones identified at -3.5 $\mathrm{km}$ and the mapped surface structures related to the San Andreas and Sargent faults are plotted in figure 4 . The locations of all these seismically active, potential fracture zones correlate closely with the potential regional fracture zones that were determined from the topography and are shown in figure 3 . The seismically active structures also suggest that the surface projection of the San Andreas rupture zone is approximately $2 \mathrm{~km}$ northeast of the mapped surface structures. Several structures related to the Sargent fault also appear to have been involved in the Loma Prieta aftershock sequence.

At the $-10-\mathrm{km}$ depth (fig. 4), seismically active structures show complex orientations that may be related to the San Andreas and Sargent fault intersection. A more organized fracture set developed along a northwest trend, which is consistent with the San Andreas fault orientation, and it extends to the northwest.

At the $-16-\mathrm{km}$ depth (fig. 4), the seismically active structures show a dominant trend that is consistent with the orientation of the slip plane derived for the main event of the Loma Prieta earthquake, N. $130 \pm 10^{\circ}$ E. (Oppenheimer, 1990). Fault structures at the $-16-$ $\mathrm{km}$ datum dip from approximately $60^{\circ}$ to $90^{\circ}$ to the southwest, and several of the dominant sets range from $75^{\circ}$ to $80^{\circ}$ southwest. These dips correlate closely with the $70 \pm 15^{\circ}$ reported by Oppenheimer (1990).

Figure 5 shows the three-dimensional spatial relationships of the topographic and seismic hypocenter analyses. Included are the surface traces of mapped fault structures, the potential regional fracture zones determined from the topographic analysis, and the seismically active structures projected to the $-3.5-\mathrm{km},-10-\mathrm{km}$, and $-16-\mathrm{km}$ datums. This model shows the spatial correlation of the surface and subsurface structural traces, as well as the southwest dip of the San
Andreas fault zone, which appears to dip more steeply from the surface to $-10 \mathrm{~km}$ than it does from $-10 \mathrm{~km}$ to $-16 \mathrm{~km}$.

\section{Subregional topographic analysis}

We analyzed the topographic low vector data by using overlapping subregions in order to define the near-surface, local, potential fracture zones. From the results, we selected potential fracture zones having clusters of six or more planes. A composite plot of these dominant local structures projected to the $427-\mathrm{m}-(1,400-\mathrm{ft}-)$ altitude datum is shown in figure 6 . The local surface structures plotted as dark blue and green in the figure are on or are southwest of the San Andreas and Sargent faults, as defined by the previous regional analyses of the topography and seismic hypocenters. These structures are postulated to be on the Pacific plate side of the San Andreas fault, which was uplifted approximately $0.4 \mathrm{~m}$ by the Loma Prieta event as determined by geodetic modeling (Lisowski and others, 1990). The potential fracture zones appear to be developing in two different structural domains. The structures in the southwest, plotted in dark blue, trend dominantly west-northwest-east-southeast and east-west and have dips ranging from $50^{\circ}$ to $60^{\circ}$. These structures appear to be normal-faulting structures that are developing in order to accommodate extension related to the uplift. The fracture sets that are plotted in green trend dominantly northeast-southwest and dip steeply $\left(70^{\circ}\right.$ to $90^{\circ}$ ). These structures appear to dominate the boundary of the Pacific plate and include the area now mapped as the San Andreas fault zone. A complex boundary zone along this section of the San Andreas fault, which includes the Sargent fault intersection, is defined by these structures. Northeast-southwest transpression and right-lateral shear could account for the development of these structures. Northeast of the San Andreas and Sargent fault zones on the North American plate is a local topographic high containing Mount Umanhum. This area appears to be a relatively competent crustal block that is bounded by several dominant structures plotted in light blue. The spatial relationship of these structural domains is shown in a generalized block diagram (fig. 7). Of necessity, our structural interpretations are limited by the extent of the analysis area, which includes only the part of the Loma Prieta earthquake rupture zone that is northwest of the main event.

\section{Conclusions}

This study of the brittle structures that are forming on a segment of the San Andreas fault, including its intersection with the Sargent fault, has provided a rigorous test of the research tools being used for structural analysis of fracture systems. These tools are being developed in order to provide quantitative methods for the remote determination of complex crustal fracture patterns from data sets that can be collected from aerial platforms, satellites, and microseismic arrays. Although the topographic analysis will not be applicable to areas of low relief and recent sedimentary deposits, these tools should contribute to the study of brittle structures in areas of moderate topographic relief. Fortunately, most seismically active continental areas have significant topographic relief.

The Loma Prieta topographic analyses have identified dominant, regional, potential fracture zones northeast of the mapped San Andreas fault zone. These potential fracture zones correlate closely both with the near-surface potential fracture zones that have been determined from seismic hypocenters and with the surface projection of the modeled fault plane that has been determined from geodetic data (Lisowski and others, 1990). It is unlikely that the seismic activity and crustal displacement related to the Loma Prieta event are occurring on new or unique crustal fractures. These events most likely are 

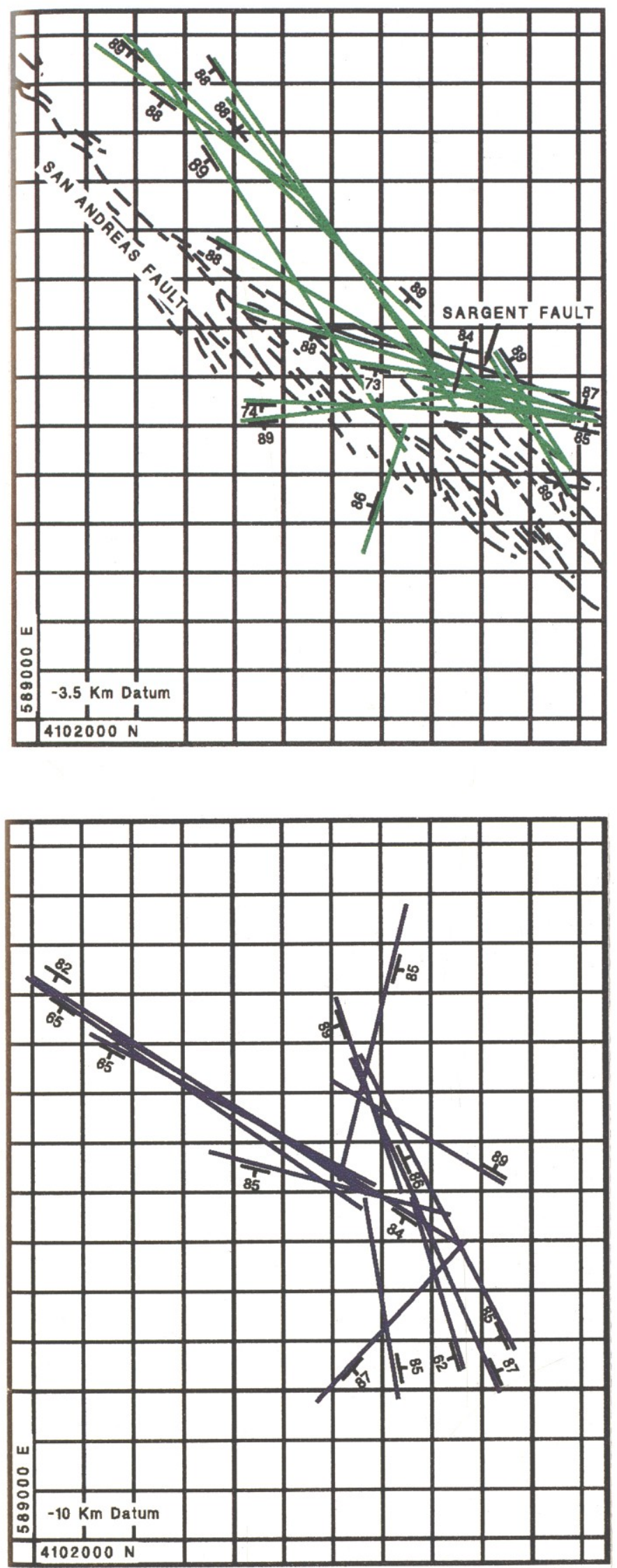

Figure 4.-Locally active, potential fracture zones and their dips projected to the $-3.5-\mathrm{km}$ datum (green), $-10-\mathrm{km}$ datum (dark blue), and $-16-\mathrm{km}$ datum (light blue). The mapped surface faults related to the San Andreas (dashed black lines) and Sargent (solid black lines) fault zones are shown on the $-3.5-\mathrm{km}$ datum. The plots are referenced to the UTM, zone 10S, 1,000-m grid.

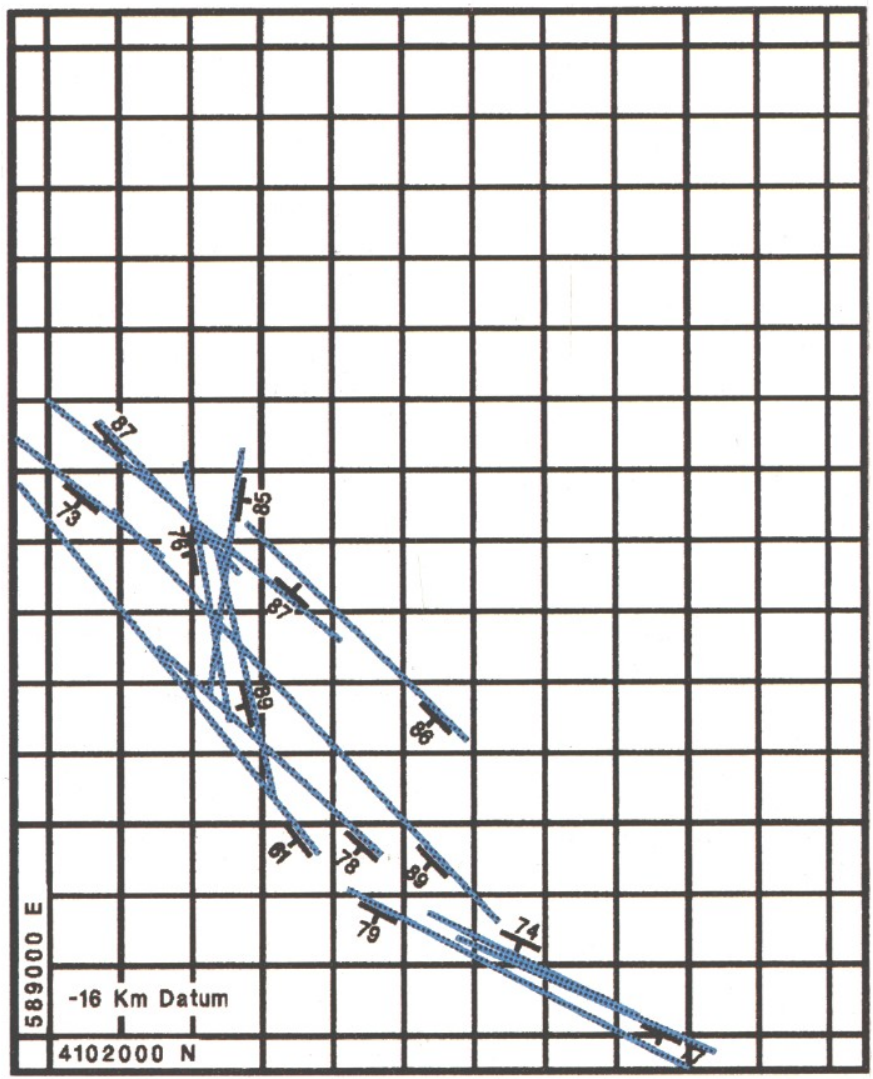




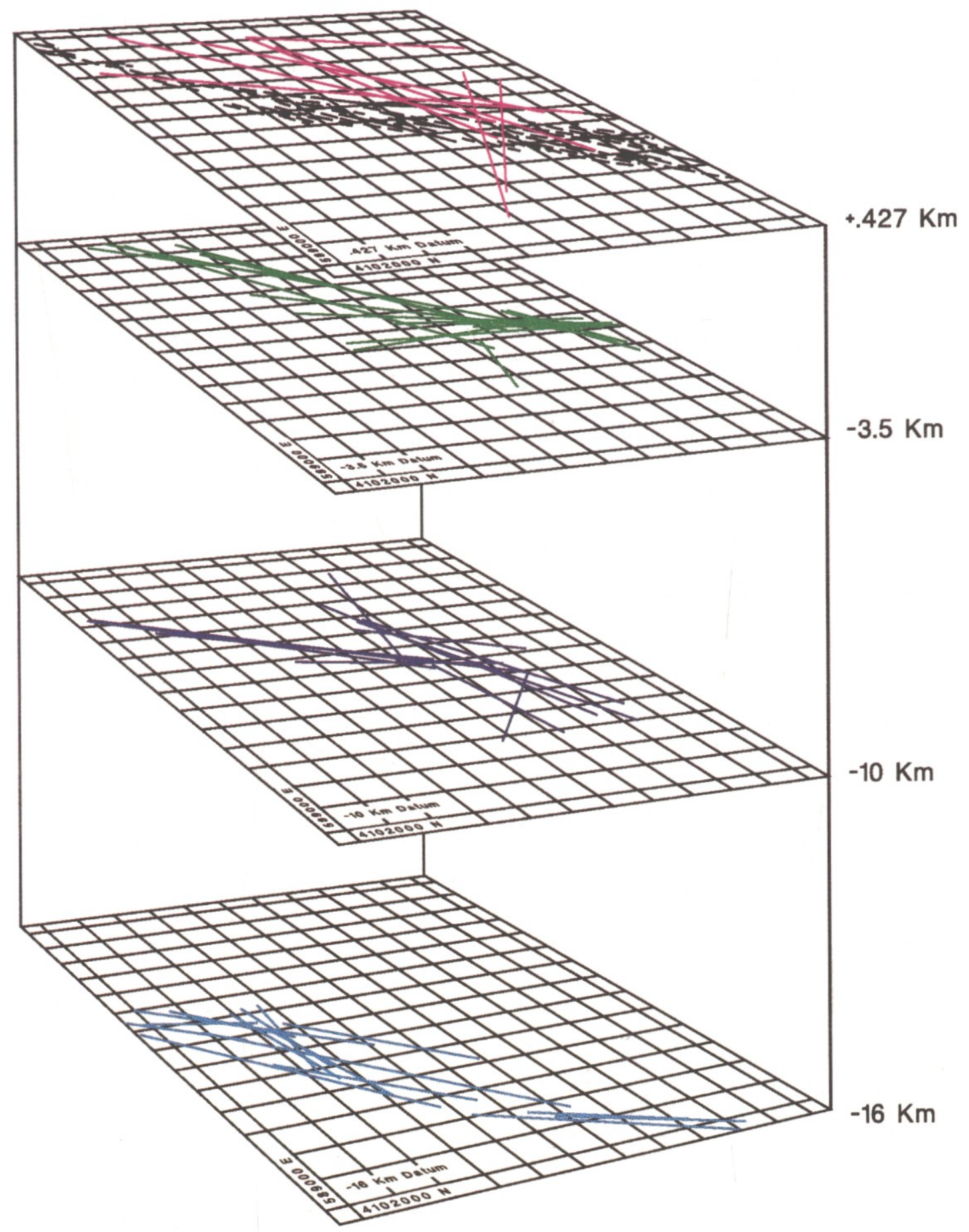

Figure 5. - Spatial relationships of the mapped surface faults related to the San Andreas and Sargent fault zones (black) and the potential regional topographic and seismically active fracture zones (colors) projected to near-surface and subsurface datums, which are referenced to the UTM, zone 10S, 1,000-m grid. 


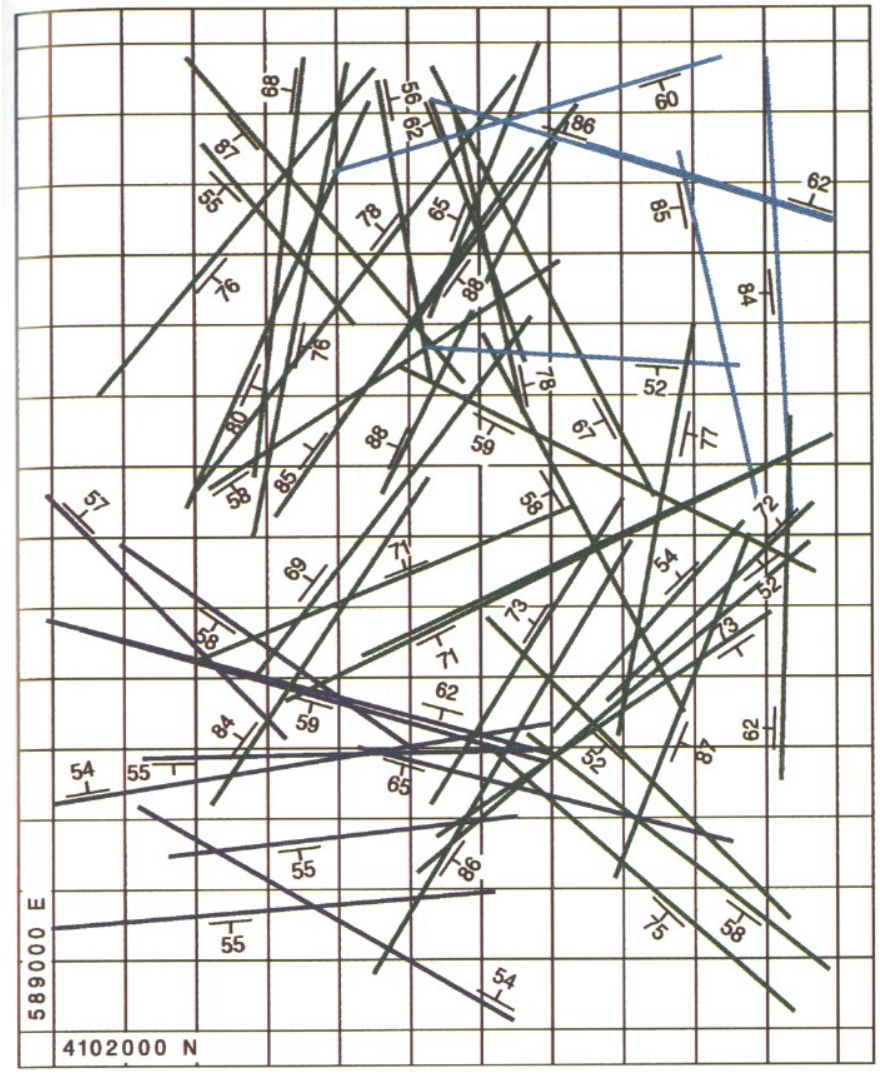

reactivating the dominant crustal weaknesses that represent the local San Andreas and Sargent fault zones. The dominant surface fracture zones that have been determined from the topographic data probably are the surface manifestation of fault zones developing in response to the right-lateral displacement on this segment of the San Andreas fault. Field studies should focus on this area for the purpose of determining whether direct evidence of right-lateral offset exists. Horizontal displacement measured on surface fractures that formed as a result of the Loma Prieta event shows no significant evidence of right-lateral displacement (Hart and others, 1990). These fractures are considered to be developing in response to effects such as lateral spreading of the ridges caused by shaking and secondary faulting. The analyses of topographic data indicate that a complex fracture domain has formed along the fault boundary in this area in order to accommodate deformation and movement of the fault blocks. Secondary motion on these and related minor fault structures that underlie the mapped San Andreas fault zone may account for the fact that the observed surface rupturing is unrelated to the primary right-lateral fault motion in this area.

Mapping of near-surface brittle structures from the subtle, but recoverable, imprint of the underlying fracture systems is a remote sensing research tool that can be applied now to most areas having moderate topographic relief. Stereo imagery collected from aerial and

4 Figure 6.-Potential fracture zones and their dips determined from the subregion analyses of topography projected to the 427-m- (1,400-ft-) altitude datum referenced to the UTM, zone $10 S, 1,000-m$ grid. The color coding is related to structural domains: Pacific plate (dark blue), boundary zone (green), and North American plate (light blue).

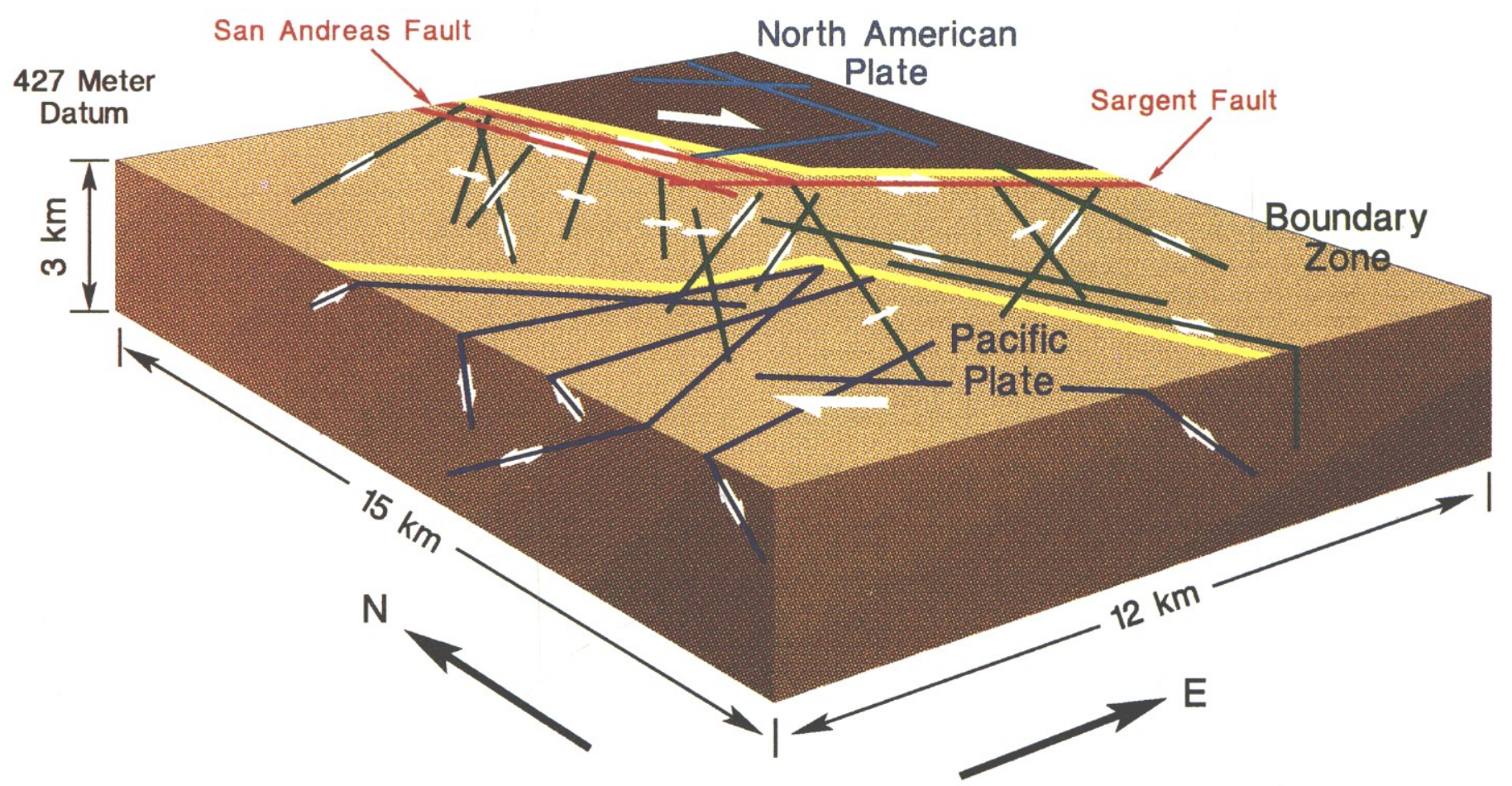

Figure 7.-Generalized structural model of the potential fracture zones determined from the topographic fracture analyses. Arrows show direction of movement. 
(or) high-resolution satellite platforms can be used to obtain the topographic data required for the analyses. In the United States, topographic data are available for most areas at a scale of 1:24,000. These data are adequate for conducting topographic fracture analyses. Larger scale topographic data may be required for analyses in areas of low relief and for defining fracture detail in local areas. Current satellite systems are capable of obtaining topographic data that has a $10-\mathrm{m}$ accuracy, and this should be useful for conducting fracture analyses of many areas. In addition, accurately located seismic hypocenters apparently contain a recoverable imprint of the local fracture systems. Both of these methods of analysis are based on the assumption that crustal fracture zones that develop under local stress fields tend to be planar over several kilometers. These fractures subtly influence erosion patterns at the surface and control the location of seismic activity at depth. By studying the spatial relationships of erosional patterns and seismic events, we have been able to recover the three-dimensional locations and orientations of these fractures. This ability will provide another valuable research tool for the investigation of complex fault systems. Data from these investigations will complement the lithologic and structural data that are being collected in the field by classic techniques.

The work presented here provides only a small window into the structural detail that should be recoverable from areas having complex fault systems. Future research hopefully will provide the key data that are needed in order to determine the neotectonic framework of seismically active areas and to provide us with better assessment of local seismic risk.

\section{Acknowledgments}

My research partner and wife, Valerie L.C. Eliason, has been responsible for much of the data preparation and analyses required for conducting this research and for completing these demonstration projects.

I would like to thank D.J. Ponti and R.E. Wells of the U.S. Geological Survey in Menlo Park, California, for identifying the areas of maximum surface rupture and for reviewing our initial analyses of the area, as well as D.H. Oppenheimer of the U.S. Geological Survey in Menlo Park, California, for providing the Loma Prieta seismic data set and for reviewing these analyses.

\section{References}

Brabb, E.E., and Hanna, W.F., 1981, Maps showing aeromagnetic anomalies, faults, earthquake epicenters, and igneous rocks in the southern San Francisco Bay region, California: U.S. Geological Survey Geophysical Investigations Map GP-932, scale 1:125,000.

Dietz, L.D., and Ellsworth. W.L., 1990. The October 17, 1989, Loma Prieta, California, earthquake and its aftershocks: Geometry of the sequence from high-resolution locations: Geophysical Research Letters, v. 17 , no. 9, p. 1417-1420.

Eliason, J.R., 1984, A technique for structural geologic analysis of topography: Pullman, Washington, USA, Washington State University, doctoral dissertation, $196 \mathrm{p}$.

Eliason, J.R., and Eliason, V.L., 1985a, A comparative study of fracture planes computed from topography and lineaments from imagery with structures and mineralization in the magnesite belt of Washington State, in International Symposium on Remote Sensing of EnvironmentRemote Sensing for Exploration Geology, 4th, San Francisco, California, USA, 1985, Proceedings: Ann Arbor, Michigan, USA, Environmental Research Institute of Michigan, p. 655-664.

-1985 b, U.S. Patent $4,698,759$, issued October 6, 1987, Process for structural geologic analysis of topography and point data.
Fehler, Michael, House, Leigh, and Kaieda, Hideshi, 1987, Determining planes along which earthquakes occur: Method and application to earthquakes accompanying hydraulic fracturing: Journal of Geophysical Research, v. 92, no. B9, p. 9407-9414.

Hart, E.W., Bryant. W.A.. Wills, C.J., and Treiman. J.A., 1990. The search for fault rupture and significance of ridgetop fissures, Santa Cruz Mountains, California, in McNutt, S.R., and Sydnor, R.H., eds., The Loma Prieta (Santa Cruz Mountains), California, earthquake of 17 October 1989: California Division of Mines and Geology, Special Publication 104, p. 83-94.

Lisowski, M., Prescott, W.H., Savage, J.C., and Johnston, M.J., 1990, Geodetic estimate of coseismic slip during the 1989 Loma Prieta, California, earthquake: Geophysical Research Letters, v. 17, no. 9, p. $1437-1440$.

Michelini, A., and Bolt, B.A., 1986, Application of the principal parameters method to the 1983 Coalinga, California, aftershock sequence: Bulletin of the Seismological Society of America, v, 76, no. 2, p. 402-420.

Oppenheimer, D.H., 1990, Aftershock slip behavior of the 1989 Loma Prieta, California, earthquake: Geophysical Research Letters, v. 17, no. 8, p. 1199-1202.

Rieken, E.R., 1985, Computer generated fault surface determinations for earthquake foci: Pullman, Washington, USA, Washington State University, master's thesis, $126 \mathrm{p}$.

U.S. Geological Survey Staff, 1989, Preliminary map of fractures formed in the Summit Road-Skyland Ridge area during the Loma Prieta, California, earthquake of October 17, 1989: U.S. Geological Survey Open-File Report 89-686, scale 1:12,000.

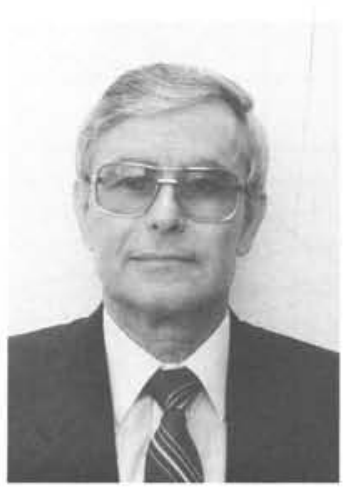

Dr. Eliason has over 30 years of experience in geological research and development. His work has included the development of quantitative digital analysis techniques for remote sensing and the assessment of geologic structures, hydrogeology, and environmental geology. Currently, his studies focus on the continued development and application of fracture analysis techniques. Dr. Eliason is co-owner of Geologic Analysis and Consulting Services in Deary, Idaho, USA. Previously, he worked for 25 years at the U.S. Department of Energy's Hanford Research Laboratory in Richland, Washington, USA, as a Senior Research Scientist and Manager of geoscience investigations. 